\title{
Positive and Negative Affects in Horse-assisted Coachings
}

\author{
Kathrin Schütz ${ }^{1}$ iD · Josanne Schmitz ${ }^{1}$ \\ Accepted: 3 May 2021 / Published online: 11 June 2021 \\ (C) The Author(s) 2021
}

\begin{abstract}
The present study examines whether horses can be implemented in coaching in order to change individuals' positive and negative affects. To this end, an experimental group $(n=46)$ received a horse-assisted coaching, whereas the control group $(n=46)$ did not receive any coaching. The short-time intervention consisted of one coaching session with a horse for a duration of two hours. Positive and negative affects were measured with the PANAS (Positive and Negative Affect Schedule) in both groups using a pre-post-test-design. Results reveal that the level of positive affects increased, and the level of negative affects decreased significantly in the intervention group when compared to the control group. This outcome suggests the possibility of improving emotions and states of mood in humans through horse-assisted coaching.
\end{abstract}

Keywords Positive affect $\cdot$ Negative affect $\cdot$ Horse-assisted coaching $\cdot$ Equine-assisted intervention $\cdot$ PANAS

\section{Positive und negative Affekte in pferdegestützten Coachings}

\section{Zusammenfassung}

In der vorliegenden Studie wird untersucht, inwiefern Pferde im Coaching eingesetzt werden können, um positive und negative affektive Zustände von Individuen zu verändern. Zu diesem Zweck nahm die Experimentalgruppe $(n=46)$ an einem pferdegestützten Coaching teil, während die Kontrollgruppe $(n=46)$ kein Coaching erhielt. Die Kurzzeitintervention bestand aus einer Coaching-Sitzung mit einem Pferd über eine Dauer von zwei Stunden. Positive und negative Affekte wurden in beiden Gruppen mit dem PANAS (Positive and Negative Affect Schedule) in einem Prä-Post-Test-Design gemessen. Die Ergebnisse zeigen, dass das Niveau der positiven Affekte in der Interventionsgruppe im Vergleich zur Kontrollgruppe signifikant anstieg und das Niveau der negativen Affekte abnahm. Dieses Ergebnis deutet auf die Möglichkeit hin, Emotionen und Gemütszustände bei Menschen durch ein pferdegestütztes Coaching zu verbessern.

Schlüsselwörter Positiver Affekt · Negativer Affekt · Pferdegestütztes Coaching · Pferdegestützte Interventionen · PANAS

\section{Introduction}

Animals can have positive effects on humans in various ways, which can lead to stress reduction, emotional open-

Availability of data and material Materials can be requested from the authors.

Kathrin Schütz

kathrin.schuetz@hs-fresenius.de

1 Psychology School, Hochschule Fresenius University of Applied Sciences, Platz der Ideen 2, 40476 Düsseldorf, Germany ing, motivation to act and sustainable learning. Further positive effects are higher self-esteem and increased control, resulting in animals being used more and more in coaching (Greiffenhagen and Buck-Werner 2011; MacDonald 2004; Otterstedt 2001). In the present study, the focus is on horses. Horses have been shown to react to human emotions, which is something that is applied in horse-assisted coaching. This form of intervention is about personality development with horses, whereby clients lead the horses through a course, for example. Subsequently, the human-horse interaction is analyzed with the help of a professional coach and therefore transferred to everyday life. 
Different behaviors and emotions can be experienced from interactions with horses, including motivation, empathy, mindfulness, social competence, trust, patience, respect, sensitivity towards others, and reductions in violent behavior (Earles et al. 2015; Gibbons et al. 2015; Hemingway et al. 2015; Vidrine et al. 2002). Horses' behavior heavily relies on the flight or fight system, consequently threatening behavior from a human may cause a horse to flee or show protective behavior such as rearing (Gomolla et al. 2011). Krüger (2018) assumes that horses do not react emotionally without reason, which can thus provide an indication about the individuals' emotional states. Furthermore, horses have been found to react particularly to human emotions (Smith et al. 2016). They are able to categorize human facial expressions into positive and negative emotional areas (Smith et al. 2016; Trösch et al. 2019), react to human nervousness (Keeling et al. 2009; von Borstel et al. 2007) and have been used in psychotherapeutic contexts and coaching for several decades, among other things due to their mirror function. Horses are able to mirror, for example, human relaxation and tension as well as emotions (Gomolla et al. 2011; Meyer 2009; Serad 2010). However, there have been few studies in the field of horse-assisted coaching and its effect on clients thus far (Schütz 2020). The Purpose of the present study was to investigate how equine-assisted coaching affects clients' positive and negative affects. In the following, affects are understood as emotional states including different sensations and feelings (Breyer and Bluemke 2016).

Emotions are defined as psychological processes involving an affective core. They are not to be understood as thought contents but are characterized by psychological experience. Each emotion can be felt through a feeling typical for it. Affective experience is therefore a necessary and sufficient condition for an emotion (Frenzel et al. 2009). Emotions serve to evaluate events and are therefore not neutral, they can also be arranged in rating scale. In evolutionary biology, humans look for events causing pleasure and avoid situations providing unpleasantness. Thus, emotions are divided into positive and negative categories. Accordingly, emotions structure and influence behavior. They do not only structure the behavior of a person, but also limit it by influencing various parameters, such as the ability to solve problems, creativity or the ability to think, which influence individual behavior (Hülshoff 2012).

In the classification of emotions, a distinction is made between dimensional and categorical concepts. The dimensional approach is used to capture general affective states, which is achieved with the help of specially designed measurement instruments. In the categorial conception it is about being able to qualitatively differentiate different emotions, such as sadness, joy, fear and disgust (Brandstätter et al. 2018). Along the so-called valence dimension, emo- tions can usually be clearly assigned to positive or negative emotions. Emotions give signals for how pleasant or unpleasant an environmental stimulus or a situation is perceived and thus have an evaluating function (Frenzel et al. 2009). According to the intensity dimension it can be determined how strong the emotion is classified as positive or negative (Brandstätter et al. 2018).

There are different theories to explain the development of emotions. With regard to the influence of horse-assisted coaching on the experience of positive and negative emotions, cognitive-physiological and cognitive emotion theories are primarily considered. The main assumption of the cognitive-physiological theory is that emotions arise from a combination of cognitive, situational factors and physiological excitation. It is assumed that a state of physiological arousal is interpreted on the basis of the available cognitions and thus evaluated. The same state of arousal can thus be perceived differently depending on its evaluation. If an individual has a plausible explanation for a physiological state of arousal, it is not evaluated by cognitions. Accordingly, emotional experience is only reported if emotive cognitions prevail simultaneously with a state of physiological arousal and are linked with each other (Schachter 1959). Cognitive emotion theories are differentiated into cognitive-evaluative and cognitive-motivational theories (Reisenzein 2010). Cognitive-evaluative theories assume that evaluations are the cause of an emotion. In this context, evaluations are value beliefs regarding a situation or event. According to the cognitive-motivational theories, emotions depend on the motivational states. In this context, motivation is understood as a future-oriented emotional evaluation. For goals to be pursued in a motivated manner, there must be an objectively evident connection between the individual realization of goals and the extension of the precautionary safeguarding of existence. This connection must be anchored in the social references to meaning and must be cognitively fathomed by the individual. In addition to these three prerequisites which lead to the anticipation of a future and higher-value state, the future effort must also be weighed against the future risk (Reisenzein 2009).

Considering how horses can react to humans, the first scientific findings on which this study is based are already apparent. Smith et al. (2016) found the first evidence in their study that horses can spontaneously distinguish positive (happy) from negative (evil) human facial expressions on photographs. Trösch et al. (2019) were able to show that horses reacted to human emotions that were presented to them in a multimodal way. Test horses saw short video sequences without sound, each showing a woman with different facial expressions. In one video positive emotions (joy, fun) were shown, followed by negative emotions (anger, rage) shown in the other video, which either matched or did not match the emotion shown in the picture. The horses 
were able to distinguish between suitable and unsuitable combinations. Gomolla et al. (2011) focused in their study on the horses' reactions to human body tension and posture. Since horses are flight animals, it was assumed that they should react specially to tension and relaxation of their counterpart. The horses were also physically tense or relaxed and thus mirrored their human counterpart. The focus here was both on people who were either sitting next to a horse or on a horse in order to check whether the horses could reflect the physical reactions of people in both variations. In the relaxation moments, for example, a hanging head, a loose tail or hanging lower lip as well as relaxed breathing could very often be observed. In the tense situations, the horses reacted with a raised head, movement impulses, upright ears or even increased breathing and tense muscles. Meyer (2009) assumes that horses reflect the inner processes and emotions of people who express themselves through their body language and react to the smallest changes. In addition, in their communication with people, horses react individually to these, even if it is the identical settings that the horses know exactly. They do not show a memorized behavior, but rather show an individual behavior that belongs to the moment of the event (Schütz et al. 2018). As flight and prey animals, horses must always pay attention to fine, nonverbal signals and above all to the body language of its opposite. They are therefore very good at nonverbal communication and reading body language (Gehrke 2009). Due to these characteristics, horses are also used in coaching. Depending on the setting, the client should lead the horse in various exercises, for example through a course. The interaction with the horse is then reflected upon with the coach. Goals can be different and can refer to self-perception and external perception, setting limits, leadership behavior or focusing emotions (Konir 2012; Schütz et al. 2020). In this setting, the horse serves as a mirror and catalyst for human behavior (Meyer 2009). The special form of horse-assisted coaching makes use of the positive effect of a human-animal relationship. The horse is seen as a coaching partner that works together with both the coach and the client. In this way the client gains insights into his interaction and communication (verbal and nonverbal) (Ewing-Chow 2014). The role of the horse within the coaching process is to serve the client as a mirror of his behavior (Serad 2010), which can be the basis for intensive self-reflection. Beier (2011) emphasizes the high proportion of self-activity, initiative and emotional involvement in the coaching process. This facilitates the memorization of experiences and insights, so that they remain available at a later time. In addition, humans can open themselves with the help of animals emotionally and develop a confidence basis to other fellow men. This in turn can be beneficial for the relationship between coach and client (Greiffenhagen and Buck-Werner 2011). Horses are particularly suitable as coaching partners, since they are able to read human signals sensitively through training and socialization as well as increased interaction with humans (Krüger et al. 2011).

The encounter with a horse can be perceived by humans as genuine and accepting, which is why they can promote the emotional exploration of the self (Rogers 2009). Horses can also be used to reproduce feelings from past relationships to the current situation. Unconscious feelings, unprocessed conflicts as well as fantasies can be made accessible and thus be picked up and processed in various intervention measures (Greiffenhagen and Buck-Werner 2011). Gehrke et al. (2018) examined 17 veterans in an eight-week program with horse-assisted psychotherapy. They wanted to find out whether the animals showed positive effects in the autonomous nervous system and whether horsemanship training led to a subjective improvement in the quality of life. The clients suffered from anxiety and PTSD. The variability of the heart rate and the positive and negative feelings were measured (using the PANAS questionnaire, which was also used in the present study). Researchers conclude that veterans who are traumatized and suffer from stress and anxiety related to PTSD benefit from horse-assisted psychotherapy on both the psychological and physical levels.

In summary, emotions can have an effect on one's own behavior. Horses react sensitively to their counterpart and they are able to identify and react to human emotions. The focus of this study was to examine the extent to which affects in persons change through horse-assisted coaching. The PANAS questionnaire has already been used in a study of horse-assisted therapy with PTSD clients but has not yet been used in horse-assisted coaching as a short-term intervention with persons without mental illness. With the help of the present study, this research gap shall now be closed. Thus, also the effectiveness of this coaching form can be analyzed.

Given that interactions with horses have positive psychological effects on aspects linked to humans' emotional states, it is hypothesized that an equine-assisted coaching is accompanied by an increase of positive affects (H1a) and a decrease of negative affects (H1b) compared to a control group. We hypothesized that equine-assisted coaching would improve positive affects $(\mathrm{H} 2 \mathrm{a})$ and decrease negative affects $(\mathrm{H} 2 \mathrm{~b})$ in a before-after comparison.

\section{Methods}

\subsection{Sample}

Participants were 61 females and 31 males with a mean age of 31.65 years $(S D=13.96 ; 66 \%$ female). They belonged either to the experimental group ( $n=46 ; 80 \%$ female) or to 
the control group ( $n=46 ; 52 \%$ female). Only those persons who were not undergoing psychotherapeutic treatment at the time of the survey took part in the study.

\subsection{Instrument}

Both the experimental group and the control group received an identical questionnaire at both measurement points. The questionnaire part at the first measurement time consisted of the query of demographic data, questions about previous experience with horses and the creation of a personal code to assign both questionnaire parts from the different measurement times. Furthermore, it contained items of the positive and negative affect schedule (PANAS; Watson and Clark 1988) in the German translation by Krohne et al. (1996). The PANAS questionnaire includes 20 adjectives describing different feelings and emotions (ten each for positive and negative feelings such as strong, alert, nervous, and jittery). The questionnaire at the second measurement point consisted of the personal code for the assignment of both parts of the questionnaire and the items of the PANAS questionnaire in order to analyze the affects again. It was pointed out before filling out the questionnaire that the items refer to the state of the person at the moment. The five-level answer scale ranges from "not at all" to "extremely". While positive affect describes an enthusiastic awake and active state, negative affect describes the extent of negative tension caused by depression, fear and anger (Breyer and Bluemke 2016; Watson and Tellegen 1985; Watson et al. 1988). There are correlations of positive affect with satisfaction, social activity and the number of pleasant events, while for negative affect there are correlations with stress, health problems and the number of unpleasant events (Watson and Tellegen 1985; Watson et al. 1988). With a reliability of $\alpha=0.86$ to $\alpha=0.93$ the questionnaire has a good internal consistency. In the present study, the reliability test showed an internal consistency of $\alpha=0.62$ at the first measurement time (t1) and at the second measurement time (t2) for positive affectivity, and an internal consistency of $\alpha=0.90$. For negative affectivity, the internal consistency at the first measurement time (t1) was $\alpha=0.81$ and at the second measurement time (t2) $\alpha=0.83$.

\subsection{Design}

A comparative study with measurement repetition in a quasi-experimental test design was conducted (Mc Burney and White 2010). The study participants were divided into an experimental group and a control group. While the experimental group consisted of participants of the horseassisted coaching, the control group consisted of randomly selected individuals. Participants were recruited from universities and by notices in stores and sports facilities. The survey was conducted using a paper-pencil questionnaire. Accordingly, group assignment was conditional on either no or no participation in coaching (treatment). This means that those who agreed to participate in coaching belonged to the experimental group. Control group participants also completed the questionnaires (as did the experimental group participants) at two measurement time points (at the same time interval as the control group)-however, they did not receive any treatment.

During the coaching sessions of the experimental group, participants were informed about the legal framework, the presentation of the study and the voluntary nature of their participation. For the first part of the questionnaire, only the questionnaire instruction was referred to in order to minimize possible effects of the experimental group. The horse-assisted coaches were psychologists. The horse part of the coaching included an exercise designed to answer the question. First, the subjects received safety instruction in handling horses. They were shown how to attach and remove the hook of the lead string, how to hold the lead string and that they were allowed to ask for advice during the whole exercise. The instruction was to do an exercise after the contact with the horse. The horse was to be led by a lead rope which was connected to the horse's halter.

Participants were given the task of slalom around four pylons, leading the horse over a plastic tarpaulin and stopping the horse over a pole lying on the ground so that the front legs were in front of the pole, and the back legs behind it (see Fig. 1). This exercise was chosen because it had a simple structure and was familiar to the horse from at least 30 of the previous coaching sessions.

After completing the exercise (see Fig. 2), participants in the experimental group received feedback from the two coaches present in order to obtain not only self-perception but also feedback on how others perceived them. This was

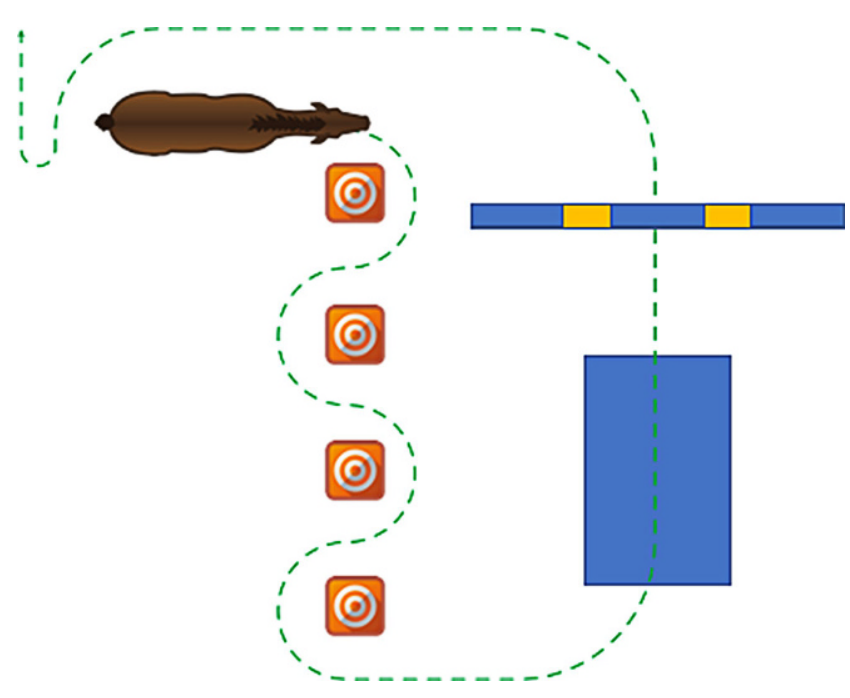

Fig. 1 Exercises implemented 
Fig. 2 Human-horse interactions in the exercises a plastic sheet $\mathbf{b}$ obstacle bar
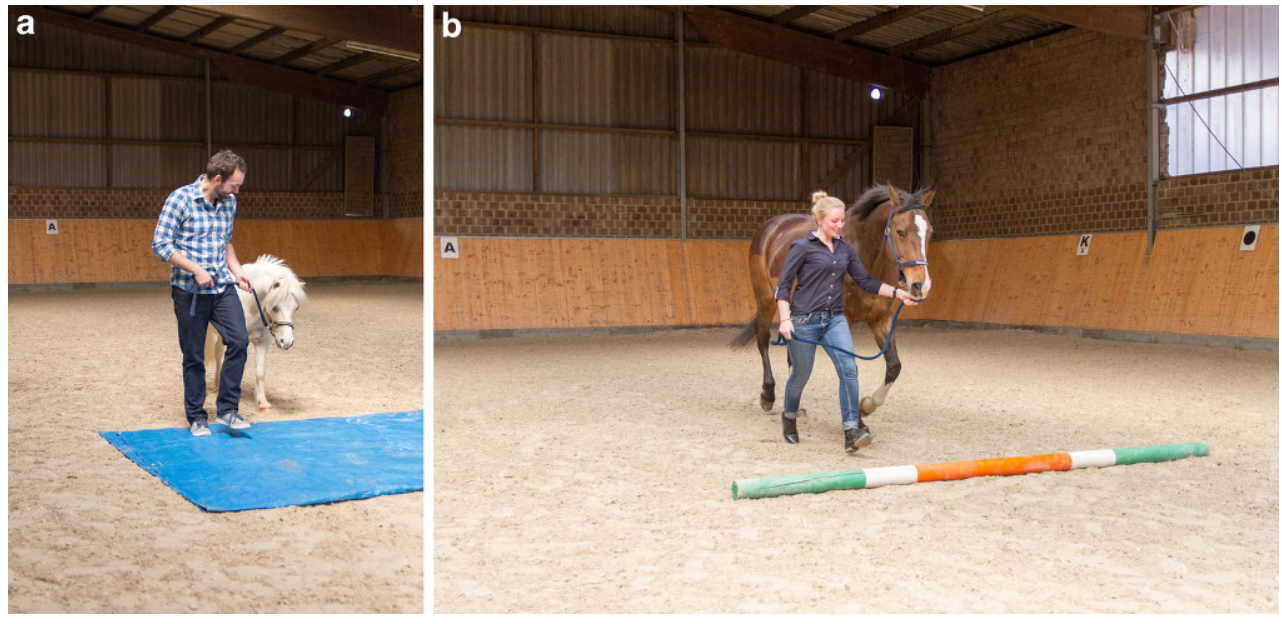

followed by the transfer into everyday life, i.e. the participants were asked where they found themselves in relation to their experiences with the horse and the feedback in everyday life or what was completely new for them. This was followed by a video analysis, which gave the participants the opportunity to analyze their own behavior as well as that of the horses from the perspective of an observer. Afterwards, participants were asked to fill out the second part of the questionnaire. The completion of the two parts of the control group questionnaires was also separated by a break of about two hours.

The horse used in the Coaching was a trained mare at the age of 22 years, which participated for nine years in coaching and which stood at least ten hours per day in the herd federation. Pasadena Miro was trained to work with different people in coaching sessions. Additional disturbing variables, such as the personality of other horses, which would have required a larger sample, could thus be excluded. Care was taken to ensure that there were always at least two days between the coaching days on which the horse was otherwise occupied (e.g. ridden or went to the meadow with the herd members or was used for other coaching sessions) in order to avoid a monotonous sequence of events and the associated conditioning effects as far as possible. Furthermore, the coaching sessions only took place if no special (negative) events had taken place before (e.g. treatment of the teeth by the horse dentist, bad and stormy weather), which could have had a corresponding influence on the horse's mood.

\subsection{Ethical Statement}

In accordance with the ethics code of American psychological association, participants of the research were volunteers and gave their informed consent. In order to protect both human and animal welfare all applicable international, national, and/or institutional guidelines for human participants and for the care and use of animals were followed, and institutional ethics was granted by the local university. Data were treated anonymously.

\section{Results}

In the experimental group, the mean value of the scale value of positive affectivity increased from measurement time $\mathrm{t} 1$ $(M=3.50, \mathrm{SD}=0.14)$ to measurement time $\mathrm{t} 2 \quad(M=3.90$, $S D=0.69)$ and that of the scale value of negative affectivity decreased (t1: $M=1.56, S D=0.52 ; \mathrm{t} 2: M=1.17, S D=0.24$ ). The mean values of the scale values, both positive and negative affectivity, of the control group did not show any relevant differences with respect to the two measurement points. At the time of measurement $\mathrm{t} 1$, the control group showed a mean value of $M=3.17(S D=0.62)$ for positive affectivity and at the time of measurement $\mathrm{t} 2$ a mean value of $M=3.17(S D=0.61)$. For negative affectivity, time of measurement $\mathrm{t} 1$ gave a mean value of $M=1.65(S D=0.58)$ and at time of measurement $\mathrm{t} 2$ a mean value of $M=1.58$ $(S D=0.56)$. Descriptive results of the two groups (mean scale values and values of the respective items) at the respective measurement times are shown in Table 1.

The experimental group differed significantly from the control group already at the first measurement time. In view of the mean values, it was shown that the experimental group had more positive affects than the control group even before the start of coaching. For this reason, two difference values were formed, which refer exclusively to positive or negative affective change. Positive affective change increased in the experimental group by the scale value $M=0.40(S D=0.88)$. There was also a strong change in the experimental group within negative affectivity $(M=-0.39$, $S D=0.47)$, whereas in the control group positive affectivity $(M=0.00, S D=0.32)$ and negative affectivity $(M=-0.07$, $S D=0.32)$ hardly changed. 
Table 1 Descriptive statistics

\begin{tabular}{|c|c|c|c|c|c|c|c|c|}
\hline & \multicolumn{4}{|c|}{ Experimental group } & \multicolumn{4}{|c|}{ Control group } \\
\hline & \multicolumn{2}{|l|}{$\overline{\text { Pre }}$} & \multicolumn{2}{|l|}{ Post } & \multicolumn{2}{|l|}{ Pre } & \multicolumn{2}{|l|}{ Post } \\
\hline & $\bar{M}$ & $S D$ & $\bar{M}$ & $S D$ & $\bar{M}$ & $S D$ & $\bar{M}$ & $S D$ \\
\hline Positive Affect & 3.50 & 1.30 & 3.90 & 0.88 & 2.55 & 0.62 & 2.75 & 0.61 \\
\hline Negative Affect & 1.51 & 1.09 & 1.57 & 0.51 & 5.66 & 0.58 & 5.44 & 0.56 \\
\hline Active (PA) & 3.26 & 0.88 & 3.76 & 0.95 & 3.02 & 0.91 & 3.20 & 0.98 \\
\hline Distressed (NA) & 1.67 & 0.76 & 1.35 & 0.67 & 2.09 & 1.01 & 1.87 & 1.05 \\
\hline Interested (PA) & 4.28 & 0.69 & 4.26 & 0.80 & 3.52 & 0.84 & 3.41 & 0.96 \\
\hline Excited (PA) & 3.74 & 0.98 & 4.04 & 0.89 & 3.26 & 0.93 & 3.07 & 0.88 \\
\hline Upset (NA) & 1.35 & 0.71 & 1.15 & 0.42 & 1.91 & 1.23 & 1.72 & 1.24 \\
\hline Strong (PA) & 3.00 & 0.89 & 3.63 & 1.12 & 3.13 & 1.05 & 3.17 & 0.93 \\
\hline Guilty (NA) & 1.30 & 0.66 & 1.11 & 0.38 & 1.41 & 0.86 & 1.35 & 0.77 \\
\hline Scared (NA) & 1.26 & 0.57 & 1.07 & 0.25 & 1.30 & 0.73 & 1.30 & 0.63 \\
\hline Hostile (NA) & 1.11 & 0.38 & 1.00 & 0.00 & 1.37 & 0.85 & 1.43 & 1.05 \\
\hline Inspired (PA) & 3.89 & 0.61 & 3.70 & 1.03 & 2.37 & 0.85 & 2.50 & 0.98 \\
\hline Proud (PA) & 2.76 & 1.02 & 3.91 & 1.09 & 2.91 & 1.17 & 3.00 & 1.17 \\
\hline Irritable (NA) & 1.70 & 1.01 & 1.09 & 0.28 & 2.07 & 1.24 & 1.91 & 1.17 \\
\hline Enthusiastic (PA) & 3.57 & 1.07 & 4.15 & 0.89 & 2.93 & 1.20 & 2.87 & 1.02 \\
\hline Ashamed (NA) & 1.24 & 0.48 & 1.13 & 0.34 & 1.13 & 0.34 & 1.15 & 0.42 \\
\hline Alert (PA) & 3.26 & 0.93 & 3.63 & 1.02 & 3.43 & 0.93 & 3.27 & 0.85 \\
\hline Nervous (NA) & 2.48 & 1.17 & 1.26 & 0.49 & 1.91 & 1.07 & 1.85 & 0.92 \\
\hline Determined (PA) & 3.39 & 1.02 & 3.87 & 0.91 & 3.57 & 0.86 & 3.50 & 0.98 \\
\hline Attentive (PA) & 3.87 & 0.78 & 4.04 & 0.84 & 3.54 & 1.13 & 3.67 & 0.82 \\
\hline Jittery (NA) & 1.85 & 1.07 & 1.48 & 0.75 & 1.89 & 1.10 & 1.80 & 0.88 \\
\hline Afraid (NA) & 1.63 & 0.95 & 1.04 & 0.21 & 1.43 & 0.69 & 1.46 & 0.78 \\
\hline
\end{tabular}

$P A$ Positive Affect, NA Negative Affect

In order to test the hypotheses, a Kolmogorov-Smirnov Adjustment Test was first applied, which showed that the values obtained (positive affectivity at measurement time $\mathrm{t} 1$ and negative affectivity at measurement times $\mathrm{t} 1$ and $\mathrm{t} 2$ ) were in line with the hypotheses. Only the scale value of positive affectivity at the second measurement time was normally distributed. Due to the lack of normal distribution, hypotheses were tested with the nonparametric MannWhitney U-test. This allowed the differences in affective experience between control and experimental group to be determined. With regard to positive affective change $(U=435.00, z=-4.89, p<0.0001, r=-0.721)$ and negative affective change $(U=580.00, z=-3.77, p<0.0001$, $r=-0.556)$ showed significant differences between the experimental group (positive affective change: $M_{\text {Rank }}=60.04$; negative affective change: $M_{\text {Rank }}=36.11$ ) and the control group (positive affective change: $M_{\text {Rank }}=32.96$; negative affective change: $M_{\text {Rank }}=56.89$ ). In summary, hypotheses $\mathrm{H} 1 \mathrm{a}, \mathrm{H} 1 \mathrm{~b}, \mathrm{H} 2 \mathrm{a}$ and $\mathrm{H} 2 \mathrm{~b}$ can be accepted.

Independent of the hypotheses put forward in advance, the influence of previous experience in dealing with horses was explored. A Mann-Whitney-U-Test showed that the previous experience had an influence on the effect of horse-assisted coaching, both in terms of positive and negative affectivity. After the coaching, positive emotions increased more significantly in persons with horse experience $(M=0.59, S D=0.44)$ than in persons without horse experience $(M=0.15, S D=1.21)$. Negative emotions were reduced more significantly in persons with horse experience $(M=-0.40, S D=0.47)$ than in persons without horse experience $(M=-0.38, S D=0.48)$. Due to the lack of normal distribution, the data were also checked with the Mann-Whitney-U-Test. The results are not significant for both positive affective change $(U=191.50, z=-1.52, p=0.128)$ and negative affective change $(U=247.00, z=-0.29, p=0.772)$.

\section{Discussion}

Out findings showed a change in positive and negative affectivity from the first to the second measurement time: positive affectivity scores increased, and negative affectivity scores decreased between pre-test and post-test for subjects who participated in horse-assisted coaching. Therefore, conclusions can be drawn that affective states could be influenced positively by participating in horse-assisted coaching. Julius et al. (2014) assume positive influence of horses on the mental and physical health of humans. By 
achieving new goals with the horse in unfamiliar surroundings, horse-assisted coaching can have positive effects on the expectation of self-efficacy (Schütz and Steinhoff 2019). Friesenhahn (2015) emphasizes gaining a sense of achievement through task accomplishment in coaching. Task accomplishment and experiences gained within the coaching are transferred into everyday working life or private life with the help of self- and external evaluation. This provides new options for action in dealing with problems, which can have psychologically relieving effects and is accompanied by increases in positive feelings immediately after coaching.

According to cognitive-motivational theories, emotions depend on motivational states. In this context, motivation is understood as a future-oriented, emotional value. For goals to be pursued in a motivated manner, there must be an objectively recognizable connection between individual goal realization and expansion of precautionary livelihood security (Reisenzein 2009). According to Schachter (1959), emotions arise from a combination of cognitive or situational factors and physiological arousal. Accordingly, a state of physiological arousal is interpreted on the basis of the available cognitions and thus evaluated. Since horses act according to their instinct and therefore continuously check the trustworthiness and leadership ability of their interaction partner, they are also called social catalysts (Schecker et al. 2014). They can have an emotionally opening and confidence-building effect (Greiffenhagen and Buck-Werner 2011), which may have led participants in equine-assisted coaching sessions to positively interpret and evaluate a state of physiological arousal.

\subsection{Limitations and Future Research}

Within this study the chosen study design should be viewed critically. The disadvantage of this study design is that it cannot be guaranteed that the dependent variable cannot also be attributed to the average different age distribution, gender differences or special personality traits between experimental and control group. Accordingly, results cannot be interpreted causally with certainty (Fisseni 2004). In addition, hypotheses $\mathrm{H} 1 \mathrm{a}$ and $\mathrm{H} 1 \mathrm{~b}$ must be viewed critically. The hypotheses that people in the experimental group had significantly higher positive affective values than people in the control group at the second time of measurement (H1a) and the statement that people in the experimental group had significantly lower negative affective values than people in the control group at the second time of measurement (H1b) should be mentioned here. These hypotheses are only based on the second measurement point. However, descriptive evaluation of mean values shows that differences in affectivity were already present at the first measurement time. In addition, Cronbach's Alpha value for positive affectivity at the first time of measurement must be viewed critically, as it is rather questionable (Schecker et al. 2014). Nonetheless, the other Cronbach's Alpha values can be rated as good.

The underlying results offer empirical evidence for positive influence of horse-assisted coaching on experiencing positive and negative emotions. Nevertheless, with regard to the results discussed against the theoretical background, further research questions as well as research topics can be investigated. In order to realize sustainable goals and behavioral change from professionally guided horse-assisted coaching, transfer of the experience to everyday life as well as the continuous application of learned knowledge in everyday life after such a coaching must be guaranteed. Since reflection and implementation or integration of new experiences into everyday life can take time, a third measurement point or a long-term study should be designed and implemented. In order to investigate long-term influence of horse-assisted coaching on the experience of positive and negative emotions, a further measurement point could be integrated with the help of PANAS two to four weeks after the second measurement of the affective experience. The results with regard to the higher values of positive affectivity due to the previous experience in handling horses proved to be insignificant. Here results could be re-examined with a further study with a larger sample. At the first measurement point, there was already a significant difference between the experimental group and the control group. In view of the mean values, it is evident that experimental group subjects showed more positive emotions than control group subjects even before the beginning of coaching. The cause for this could be investigated and the question could be asked whether merely the anticipation or excitement regarding participation in horse-assisted coaching is sufficient to achieve a higher value of the positive affective experience. In order to examine whether the cause is generally linked to the experience of new experiences or explicitly to the participation in horse-assisted coaching, a comparative study could be conducted between horsesupported coaching and another form of coaching or intervention. Furthermore, methodological procedure can be changed or its influence on affective experience can be investigated. In a comparative study with various exercises in the context of horse-supported coaching, it can be determined, for example, whether certain exercises particularly promote emotional experience. The setting may also have influenced the experience of positive and negative emotions. A possible further research could therefore be to compare the effectiveness of group coaching with that of individual coaching and to examine their effect on affectivity. Participants may find it easier to relax within a one-on-one coaching session because they do not have to fear a so- 
cial evaluation. This could possibly lead to higher positive values of the affective experience.

In addition, the effect of horse-assisted coaching on the experience of positive and negative emotions could be examined on a gender-specific basis. Only a few men participated in the present study, which is why no analysis of gender differences was possible. A further investigation of the gender differences could be interesting here. In addition, the influence of the feedback units could be checked by the coach. In this respect, self-perception and perception of others could be analyzed and a causal connection to the experience of positive and negative emotions could be drawn. Furthermore, the effect of positive versus negative feedback on the affective state could be examined.

\section{Conclusion}

In summary, considering the results presented here, it can be said that horse-assisted coaching can have positive effects on clients' affects. The proof of an increase of positive affects as well as the reduction of negative affects within horse-assisted coaching are further scientifically founded pro-arguments for the so far hardly investigated form of intervention. Despite the knowledge gained in this study, many questions remain open in the field of equine-assisted coaching, which has been little researched so far. Therefore, further empirical studies on this topic should follow.

Funding Not applicable; there was no funding.

\section{Declarations}

Conflict of interest K. Schütz works as a horse-assisted coach, J. Schmitz declares that there were no conflicts of interest in the undertaking of this research or publication of this paper.

Ethical standards According to the specifications of Hochschule Fresenius, University of Applied Sciences, the study did not have to be reviewed by the ethics committee. Participants provided informed consent before taking part in the study.

Open Access This article is licensed under a Creative Commons Attribution 4.0 International License, which permits use, sharing, adaptation, distribution and reproduction in any medium or format, as long as you give appropriate credit to the original author(s) and the source, provide a link to the Creative Commons licence, and indicate if changes were made. The images or other third party material in this article are included in the article's Creative Commons licence, unless indicated otherwise in a credit line to the material. If material is not included in the article's Creative Commons licence and your intended use is not permitted by statutory regulation or exceeds the permitted use, you will need to obtain permission directly from the copyright holder. To view a copy of this licence, visit http://creativecommons.org/licenses/by/4. $0 /$.

\section{References}

Beier, D. (2011). Überholen mit 1 PS. Lengerich: Pabst.

von Borstel, U. U., Duncan, I. J.H., Shoveller, A. K., Millman, S. T., \& Keeling, L. J. (2007). Transfer of nervousness from competition rider to the horse. In Conference Proceedings 3rd International Equitation Science Conference, East Lansing, MI USA, Michigan State University Vol. 16.

Brandstätter, V., Schüler, J., Puca, R. M., \& Lozo, L. (2018). Motivation und Emotion. Berlin, Heidelberg, New York: Springer.

Breyer, B., \& Bluemke, M. (2016). Deutsche Version der Positive and Negative Affect Schedule PANAS (GESIS Panel). Zusammenstellung sozialwissenschaftlicher Items und Skalen. https://doi.org/ 10.6102/zis242.

Earles, J. L., Vernon, L. L., \& Yetz, J.P. (2015). Equine-assisted therapy for anxiety and posttraumatic stress symptoms. Journal of Traumatic Stress. https://doi.org/10.1002/jts.21990.

Ewing-Chow, S. A. (2014). Truth tellers: coaching with horses. Coachcampus. https://coachcampus.com/coach-portfolios/researchpapers/suzanne-a-ewing-chow-truth-tellers-coaching-withhorses/. Accessed 27 Sept 2020.

Fisseni, H.-J. (2004). Lehrbuch der psychologischen Diagnostik. Mit Hinweisen zur Intervention. Göttingen: Hogrefe.

Frenzel, A. C., Götz, T., \& Pekrun, R. (2009). Emotionen. In E. Wild \& J. Möller (Eds.), Pädagogische Psychologie (pp. 205-231). Berlin, Heidelberg, New York: Springer.

Friesenhahn, J. (2015). Coaching mit Pferden. Eine Ergänzung zu Prof. Dr. Kannings Beitrag im Coaching-Magazin 4/2014. Coaching Magazin, 4, 45-47.

Gehrke, E. K. (2009). Developing coherent leadership in partnership with horses-A new approach to leadership training. Journal of Research in Innovative Teaching, 2, 222-233.

Gehrke, E. K., Noqueza, A.E., Rankea, P.L., \& Myers, M.P. (2018). Measuring the psychophysiological changes in combat veterans participating in an equine therapy program. Journal of Military, Veteran and Family Health. https://doi.org/10.3138/jmvfh.20170015.

Gibbons, J.L., Cunningham, C. A., Paiz, L., Poelker, K. E., \& Cardenas, M. A. M. (2015). Before he fought every day with the horse and me: reducing violence in a Guatemalan community through a horse handling program. Human Animal Interaction Bulletin, $3(2), 37-55$.

Gomolla, A., Keser, B., Haag, A., Irschei, J., \& Fürst, J. (2011). Das Pferd als Spiegel des Menschen - Reaktion auf Körperspannung und -haltung. Great Horses. http://www.great-horses.org/ media/Downloads/Spiegelfunktion\%20-\%20WEB.pdf. Accessed 27 Sept 2020.

Greiffenhagen, S., \& Buck-Werner, O.N. (2011). Tiere als Therapie. Nerdlen: Kynos.

Hemingway, A., Meek, R., \& Hill, C.E. (2015). An exploration of an equine-facilitated learning interven-tion with young offenders. Society \& Animals. https://doi.org/10.1163/15685306-12341382.

Hülshoff, T. (2012). Emotionen. München: Ernst Reinhardt.

Julius, H., Beetz, A., Kotrschal, K., Tuner, D. C., \& Uvnäs-Moberg, K. (2014). Bindung zu Tieren. Göttingen: Hogrefe.

Keeling, L. J., Jonare, L., \& Lanneborn, L. (2009). Investigating horsehuman interactions: the effect of a nervous human. Veterinary Journal. https://doi.org/10.1016/j.tvj1.2009.03.013.

Konir, G. (2012). Pferdegestütztes Coaching. Menschliche Potenzialentwicklung durch tierische Hilfe. Norderstedt: Books on Demand.

Krohne, H. W., Egloff, B., Kohlmann, C.-W., \& Tausch, A. (1996). Untersuchung mit einer deutschen Form der Positive and Negative Affect Schedule (PANAS). Diagnostica, 42, 139-156.

Krüger, K. (2018). Erfasst ein Pferd die menschliche psyche? [Can horses capture human mental states?]. In C. Opgen-Rhein, M. Kläschen \& M. Dettling (Eds.), Pferdegestützte Therapie bei 
psychischen Erkrankungen [Horse-assisted therapy for mental illnesses] (2nd edn., pp. 23-35). Stuttgart: Schattauer.

Krüger, K., Flauger, B., Farmer, K., \& Maros, K. (2011). Horses (Equus caballus) use human local enhancement cues and adjust to human attention. Animal Cognition, 14, 187-201.

MacDonald, P. M. (2004). The effects of equine-facilitated therapy with at-risk adolescents: A summary of empirical research across multiple centers and programs. Philadelphia: University of Pennsylvania School of Veterinary Medicine. The Center for the Interaction of Animals and Society (CIAS)

Mc Burney, D.H., \& White, T.L. (2010). Research methods. Wadsworth: Belmont.

Meyer, S. (2009). Pferde als Medium im Coaching: natürlich, ehrlich und nachhaltig! Coaching-Magazin, 4, 42.

Otterstedt, C. (2001). Tiere als therapeutische Begleiter. Stuttgart: Kosmos.

Reisenzein, R. (2009). Emotions as metarepresentational states of mind: Naturalizing the belief-desire theory of emotion. Cognitive Systems Research, 10, 6-20.

Reisenzein, R. (2010). Moralische Gefühle aus der Sicht der kognitivmotivationalen Theorie der Emotion. In M. Iorio \& R. Reisenzein (Eds.), Regel, Norm, Gesetz (pp. 257-283). Frankfurt a.M.: Peter Lang.

Rogers, C.R. (2009). Eine Theorie der Psychotherapie, der Persönlichkeit und der zwischenmenschlichen Beziehungen. München: Reinhardt.

Schachter, S. (1959). Psychology of affiliation experimental studies of the sources of gregariousness. Stanford: Stanford University Press.

Schecker, H., Parchmann, I., \& Krüger, D. (2014). Formate und Methoden naturwissenschaftsdidaktischer Forschung. In D. Krüger, I. Parchmann \& H. Schecker (Eds.), Methoden in der naturwissenschaftsdidaktischen Forschung (pp. 1-15). Berlin, Heidelberg, New York: Springer.

Schütz, K. (2020). Pferde, Forschung \& Psychologie. Wissenschaftliche Befunde zu Fähigkeiten von Pferden und deren Wirkung auf Menschen (2nd edn.). Norderstedt: Books on Demand.
Schütz, K., \& Steinhoff, J. (2019). Einfluss von pferdegestützten Coachings auf die Selbstwirksamkeitserwartung. Coaching I Theorie \& Praxis. https://doi.org/10.1365/s40896-019-0028-5.

Schütz, K., Rötters, A., \& Oebel, L. (2018). Können Pferde als Co-Trainer agieren? Individuelle Reaktionen von Pferden in der Persönlichkeitsentwicklung auf unterschiedliche Klienten. Tiergestützte Therapie, Pädagogik \& Fördermaßnahmen, 1, 22-26.

Schütz, K., Rahders, F., Laborde, S., \& Mosley, E. (2020). Emotional competences training in equestrian sport-A preliminary study. International Journal of Sport and Exercise Psychology. https:// doi.org/10.1080/1612197X.2020.1819367.

Serad, L. (2010). Aspects of using animal-assisted interventions in a coaching model. Unpublished masterthesis. Philadelphia: University of Pennsylvania.

Smith, A.V., Proops, L., Grounds, K., Wathan, J., \& McComb, K. (2016). Functionally relevant responses to human facial expression of emotion in the domestic horse (Equus caballus). Biology Letters. https://doi.org/10.1098/rsbl.2015.0907.

Trösch, M., Cuzol, F., Parias, C., Calandreau, L., Nowak, R., \& Lansade, L. (2019). Horses categorize human emotions crossmodally based on facial expression and non-verbal vocalizations. Animals. https://doi.org/10.3390/ani9110862.

Vidrine, M., Owen-Smith, P., \& Faulkner, P. (2002). Equine-facilitated group psychotherapy: applications for therapeutic vaulting. Issues in Mental Health Nursing. https://doi.org/10.1080/ 01612840290052730.

Watson, D., \& Clark, L. A. (1988). Development and validation of brief measures of positive and negative affect: the PANAS scales. Journal of Personality and Social Psychology, 54(6), 1063-1070.

Watson, D., \& Tellegen, A. (1985). Toward a consensual structure of mood. Psychological Bulletin, 98, 219-235.

Watson, D., Clark, L.A., \& Tellegen, A. (1988). Development and validation of brief measures of positive and negative affect: The PANAS Scales. Journal of Personality and Social Psychology, 54, 1063-1070.

Publisher's Note Springer Nature remains neutral with regard to jurisdictional claims in published maps and institutional affiliations. 